\title{
A systematic literature review on strategies to avoid look-alike errors of labels
}

\author{
Karin H. M. Larmené-Beld ${ }^{1,2} \cdot$ E. Kim Alting ${ }^{2} \cdot$ Katja Taxis $^{2}$
}

Received: 8 January 2018 / Accepted: 25 April 2018 / Published online: 12 May 2018

(C) The Author(s) 2018

\begin{abstract}
Purpose Unclear labeling has been recognized as an important cause of look-alike medication errors. The aim of this literature review is to systematically evaluate the current evidence on strategies to minimize medication errors due to look-alike labels.

Methods A literature search of PubMed and EMBASE for all available years was performed independently by two reviewers. Original studies assessing strategies to minimize medication errors due to look-alike labels focusing on readability of labels by health professionals or consumers were included. Data were analyzed descriptively due to the variability of study methods.

Results Sixteen studies were included. Thirteen studies were performed in a laboratory and three in a healthcare setting. Eleven studies evaluated Tall Man lettering, i.e., capitalizing parts of the drug name, two color-coding, and three studies other strategies. In six studies, lower error rates were found for the Tall Man letter strategy; one showed significantly higher error rates. Effects of Tall Man lettering on response time were more varied. A study in the hospital setting did not show an effect on the potential look-alike sound-alike error rate by introducing Tall Man lettering. Color-coding had no effect on the prevention of syringe-swaps in one study.

Conclusions Studies performed in laboratory settings showed that Tall Man lettering contributed to a better readability of medication labels. Only few studies evaluated other strategies such as color-coding. More evidence, especially from real-life setting is needed to support safe labeling strategies.
\end{abstract}

Keywords Look-alike $\cdot$ Label $\cdot$ Tall Man $\cdot$ Color coding $\cdot$ Medication

\section{Introduction}

Good labeling of medication is an important aspect of medication safety. The American Food and Drug Administration (FDA) estimated that $20 \%$ of medication errors may be attributed to confusing packaging and poor labeling; others suggested even higher rates $[1,2]$. Commonly, look-alike labels due to similar drug names, e.g. ceftazidime - ceftriaxone

Electronic supplementary material The online version of this article (https://doi.org/10.1007/s00228-018-2471-z) contains supplementary material, which is available to authorized users.

Karin H. M. Larmené-Beld

k.h.m.beld@isala.nl

1 Department of Clinical Pharmacy, Isala Hospital, Dokter van Heesweg 2, 8025 AB Zwolle, The Netherlands

2 Faculty of Mathematics and Natural Sciences, PharmacoTherapy, -Epidemiology and -Economics, Groningen Research Institute of Pharmacy, University of Groningen, Groningen, The Netherlands or other readability issues are a cause for these errors. The clarity of labels on the primary containers of medications, also called primary labels, is particularly important for healthcare professionals. Primary labels, e.g., on vials, ampoules, syringes, or infusion bags are used in the step of medication administration to the patient. Misreading labels resulting in the administration of the wrong drug can have serious consequences for patients [3-5].

Various measures have been suggested to enhance the readability of labels and reduce errors due to look-alike labels $[3,4]$. A technical solution is the use of a closedloop system with barcode technology. But this is currently not widely implemented. Furthermore, in emergency situations, there may not be sufficient time to use barcode systems. Therefore, readability of the labels remains important. But internationally, there is no consensus about the content and form of labels. Guidelines of the FDA and European Medicine Agency (EMA) do not give conclusive advice on how to prevent look-alike errors $[5,6]$. Strategies such as Tall Man lettering and color-coding are seen as potential solutions. Tall Man lettering aims to 
maximize the difference between two similar drug names by capitalizing part of the drug names [7]. This could avoid mixing up two confusing drug names. Several organizations endorsed Tall Man lettering including the Joint Commission and the Institute for Safe Medication Practices (ISMP) [6-8]. Color-coded labels are used in anesthesia to distinguish between different substance classes as described in an international standard (ISO 26825) [9]. Also, best practices are available with design features to improve the design of labels and claim that this would improve patient safety [10]. A number of systematic reviews have addressed the related issue of sound-alike drug names, i.e., the problem of phonetic similarity of drug names $[11,12]$. Another study addressed all types of dispensing errors [13]. Some of the evidence about Tall Man lettering has been summarized in an Editorial [14]. But no recent systematic review has addressed the question how medication labels, in particular primary labels on syringes, ampoules, or infusion bags, should look like to prevent errors. Therefore, the aim of this literature review was to systematically evaluate the current evidence for strategies to minimize medication errors due to look-alike labels.

\section{Literature search method}

\section{Search strategy}

This systematic review focused on primary labels on medication containers, e.g., syringes, ampoules, or infusion bags regardless whether they were produced by the industry, the hospital pharmacy department, or on the wards. The literature search was conducted on 14 September 2015 for all available years in PubMed and EMBASE following PRISMA guidelines [15]. We used the MeSH index terms 'medication error' and 'drug labeling' in combination with the free index terms 'barcoding' or 'sound alike' or 'look alike' or 'text enhancement' or 'enhanced text' or 'drug name confusion' or 'colorcoding' mentioned in the abstract or title of the study. To prevent missing possible studies about look-alikes, the term sound-alike was added as a search term as these terms are often used as combinations. In addition, the list of references of all included studies and review articles were screened to identify additional references. An example of the search strategy is added as Appendix.

\section{Inclusion criteria}

Original studies assessing strategies to minimize medication errors due to look-alike labels focusing on readability of the primary labels by healthcare professionals or consumers were included. Studies had to report a quantitative outcome related directly or indirectly to medication errors. There were no restrictions on the study design or study setting (e.g., hospital, community pharmacy, laboratory) or the origin of the label (e.g., industry, pharmacy, ward).

\section{Exclusion criteria}

Studies written in other languages than English were excluded. Studies were also excluded if they involved case studies or causes of medication errors other than look-alike errors, such as sound-alike errors or failing communication between doctors and nurses.

Two reviewers (KLB, EKA) screened the titles and abstracts of the retrieved records independently [16]. Full texts of all potentially eligible records were also examined independently by the two reviewers. Disagreements were resolved by consensus.

\section{Definition medication error}

Medication errors were defined as a discrepancy between the drug therapy received by a patient and the drug therapy intended by the prescriber [1]. This was extrapolated to the setting of the labels by any discrepancy in readability by intended variation and distracting variation in the label by any strategy, e.g., color, Tall man lettering.

\section{Data extraction}

The following data were extracted using an Excel spreadsheet: first author's surname, publication year, country of origin, setting, participants, sample size, type of strategy to prevent look-alike errors, tested product, and drug names tested. We extracted all outcomes directly and indirectly related to medication errors. The outcomes of the studies were extracted, with no manipulation; e.g., the error rates as reported in the study were extracted without adjustment. Extraction was done by EKA and verified by KLB. Disagreements were resolved by discussion between the two reviewers and a third reviewer (KT) until consensus was reached.

\section{Data synthesis and analysis}

The studies were grouped based on the type of intervention tested (e.g., Tall Man lettering, color) and the type of outcome. Error (rate) and response times were used in the majority of the included studies. Overall error rates were included in the results of the review because not all included studies reported on different subtypes of error. For one study, the authors were contacted for missing information but without response. A note has been made to the results. Due to the high variability of the design of the included 
studies, it was not possible to perform a meta-analysis. Therefore, data were analyzed descriptively.

\section{Results}

The literature search resulted in a total of 255 studies. The full text of 18 articles were reviewed and 16 articles were included in the systematic review (Fig. 1).

The main characteristics of the included studies are described in Table 1 . The majority of studies were conducted in the UK and USA, namely five each [18-20, 22, 24-27, 31, 32]. The remaining six studies were performed in Canada, China, India, Ireland, and Norway [17, 21, 23, 28-30]. Of the sixteen studies, half used healthcare professionals for the tests and half used non-healthcare professionals. All studies were controlled laboratory experiments, except three studies which were conducted in a hospital environment. The strategies which were tested were Tall Man lettering, color-coding, variations in the background of the label, and the use of symbols.

The general study design and the study methods varied widely between studies. This included the number of participants, the number of experiments, the type of medication names, and the test conditions. The most important details are summarized per study in Tables 1 and 2 and in Table 3 and 4 in the Appendix.

\section{Tall man lettering}

Eleven studies evaluated the use of Tall Man lettering (Tables 1 and 2 and Table 3 (Appendix)) [18-20, 22, 24, 25, 27-29, 31, 32]. A wide range of different drug names were tested. Most studies tested pairs of similar drug names, but two studies also tested Tall Man lettering on the same name, i.e., presenting the drug name once in Tall Man lettering and once in non-Tall Man lettering [19, 24].

Some studies tested variations of Tall Man lettering, e.g., capitalizing different parts of the drug name [25, 29]. Some studies tested additional conditions such as with and without time pressure or previous knowledge about the purpose of Tall Man lettering $[19,27]$. The most common outcomes tested were error rate and response time. Some studies assessed subtypes of errors, such as commission and omission errors, others only reported overall error rate. In the tables, only overall error rates are reported. One study tested the number of items correctly selected. Other outcomes included eye movements, hospital admissions, and change detection (Table 2).

\section{Error rate}

Medication error rates ranged from 3 to $22 \%$ for Tall Man lettering and from 3 to $24 \%$ for non-Tall Man lettering. Six out of seven experiments showed that participants made significantly fewer errors when the drug names contained Tall Man letters, than when the drug names were displayed in lowercase letters $[18,19,24,25,29]$. From these six experiments three were performed by healthcare professionals $[24,25,29]$ and three were performed by younger and older adults [24], university students [22] and engineering students [29]. One study in non-healthcare professionals found a significantly higher error rate with Tall Man lettering. Only one study was performed in a hospital setting and resulted in no beneficial effect for Tall Man lettering to reduce potential look-alike sound-alike error rates [31]. Several methodological limitations may contribute to these results $[14,31]$.
Fig. 1 Flow chart summarizing study selection

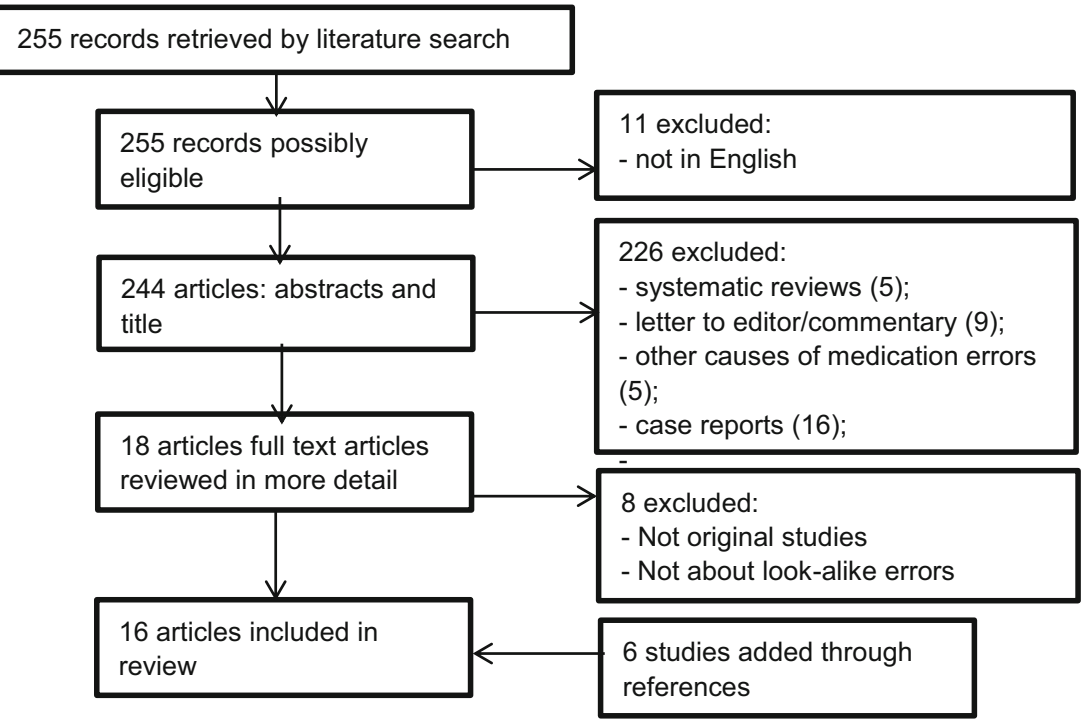


Table 1 Overview of included studies

\begin{tabular}{|c|c|c|c|c|c|c|}
\hline First author & Publication year & Country & Setting & Method of testing & Participants & Strategy \\
\hline Fasting [17] & 2000 & Norway & Hospital & Checklist on anesthetic chart & Anesthesiologists & Color-coding \\
\hline Filik [18] & 2004 & UK & Laboratory & $\begin{array}{l}\text { Mock drug packs with } \\
\text { similar names }\end{array}$ & Non-healthcare professionals & Tall Man lettering \\
\hline \multirow[t]{2}{*}{ Filik [19] } & \multirow[t]{2}{*}{2006} & \multirow[t]{2}{*}{ UK } & \multirow[t]{2}{*}{ Laboratory } & \multirow[t]{2}{*}{ Pairs of generic drug names } & Non-healthcare professionals & Tall Man lettering \\
\hline & & & & & Non-healthcare professionals & Tall Man + color \\
\hline Gabriele [20] & 2006 & USA & Laboratory & Look-alike drug names & Acute care hospital nurses & $\begin{array}{l}\text { Typographic including } \\
\text { Tall Man lettering }\end{array}$ \\
\hline Momtahan [21] & 2008 & Canada & Laboratory & $\begin{array}{l}\text { Available ampoules and } \\
\text { vials in hospital setting }\end{array}$ & Registered nurses & Contrasting background \\
\hline Schell [22] & 2009 & USA & Laboratory & Confusable drug name pairs & Non-healthcare professionals & Tall Man lettering \\
\hline Shannon [23] & 2009 & Ireland & Hospital & Questionnaire & Physicians & Color-coding \\
\hline \multirow[t]{2}{*}{ Filik [24] } & \multirow[t]{2}{*}{2010} & \multirow[t]{2}{*}{ UK } & \multirow[t]{2}{*}{ Laboratory } & Pairs of similar drug names & Young and older adults & Tall Man lettering \\
\hline & & & & Confusable drug name pairs & Healthcare professionals & Tall Man lettering \\
\hline Darker [25] & 2011 & UK & Laboratory & Confusable drug name pairs & Healthcare professionals & Tall Man lettering \\
\hline Cardarelli [26] & 2011 & USA & Laboratory & $\begin{array}{l}\text { Symbols for medication } \\
\text { indications }\end{array}$ & Older patients & $\begin{array}{l}\text { Symbol use } \\
\text { (TCOM system) }\end{array}$ \\
\hline Irwin [27] & 2013 & UK & Laboratory & Target drug names & $\begin{array}{l}\text { Non-pharmacists and } \\
\text { pharmacy staff }\end{array}$ & $\begin{array}{l}\text { Typographic including } \\
\text { Tall Man lettering }\end{array}$ \\
\hline Or [28] & 2014 & China & Laboratory & Pairs of similar drug names & $\begin{array}{l}\text { Non-healthcare professionals } \\
\text { and registered nurses }\end{array}$ & $\begin{array}{l}\text { Typographic including } \\
\text { Tall Man lettering }\end{array}$ \\
\hline Or [29] & 2014 & China & Laboratory & Pairs of similar drug names & Non-healthcare professionals & Tall Man lettering \\
\hline Gupta [30] & 2015 & India & Laboratory & Ampoules in hospital & Physicians (residents) & Contrasting background \\
\hline Zhong [31] & 2015 & USA & Hospital & $\begin{array}{l}\text { Look-alike and sound-alike } \\
\text { drug pairs }\end{array}$ & $\begin{array}{l}\text { Clinical pharmacists, } \\
\text { physicians }\end{array}$ & Tall Man lettering \\
\hline DeHenau [32] & 2016 & USA & Laboratory & Comparable drug labels & $\begin{array}{l}\text { Healthcare professionals } \\
\text { and laypeople }\end{array}$ & Tall Man lettering \\
\hline
\end{tabular}

TCOM tachygraphic color organized medication

\section{Response time}

Response times ranged from 1.2 to $31 \mathrm{~s}$ for Tall Man lettering and from 1.3 to $47 \mathrm{~s}$ for non-Tall Man lettering. In three out of nine studies, response time was significantly shorter for Tall Man lettering compared to non-Tall Man lettering [19, 24, 32]; in four studies, there was no difference $[18,19,27]$; and in two studies, response time was significantly longer for Tall Man lettering [24, 28]. One study found that when participants did not know about the purpose of Tall Man lettering, the response times were similar for lowercase and Tall Man lettering. But when told, the response times were shorter for Tall Man lettering [19].

\section{Variation in Tall Man lettering}

Other text enhancement methods (larger lowercase, boldface, and colored lettering) had also lower medication error rates and shorter response times compared to the lowercase condition [28, 29]. The use of boldface plus Tall Man lettering performed best [29].

\section{Other outcome measures}

Eye movement experiments (eye tracking system to determine fixation points) showed that participants spent less time fixating on the "distractor drug packs" (wrong pack) with Tall Man letters than on "distractor drug packs" with lowercase names (1.42 vs. $1.90 \mathrm{~s}, p<0.005)$. Also the number of fixations was fewer for the drug packs with Tall Man letters than for the drug packs with lowercase lettering (4.6 fixations vs. 5.6 fixations, $p<0.05)$ [18].

\section{Other strategies}

Two studies tested color-coding (Table 4, Appendix) [17, 23]. One study showed no reduction in incidence and severity of drug errors after introducing color-coded syringe labels [17]. A questionnaire-based study reported that physicians still experienced medication errors and near misses after introduction of a color-coded system [23]. Other studies performed experiments that focused on contrasting backgrounds on ampoules. The time it took the participants to identify the information on the existing labels (text directly printed on glass or on a clear 


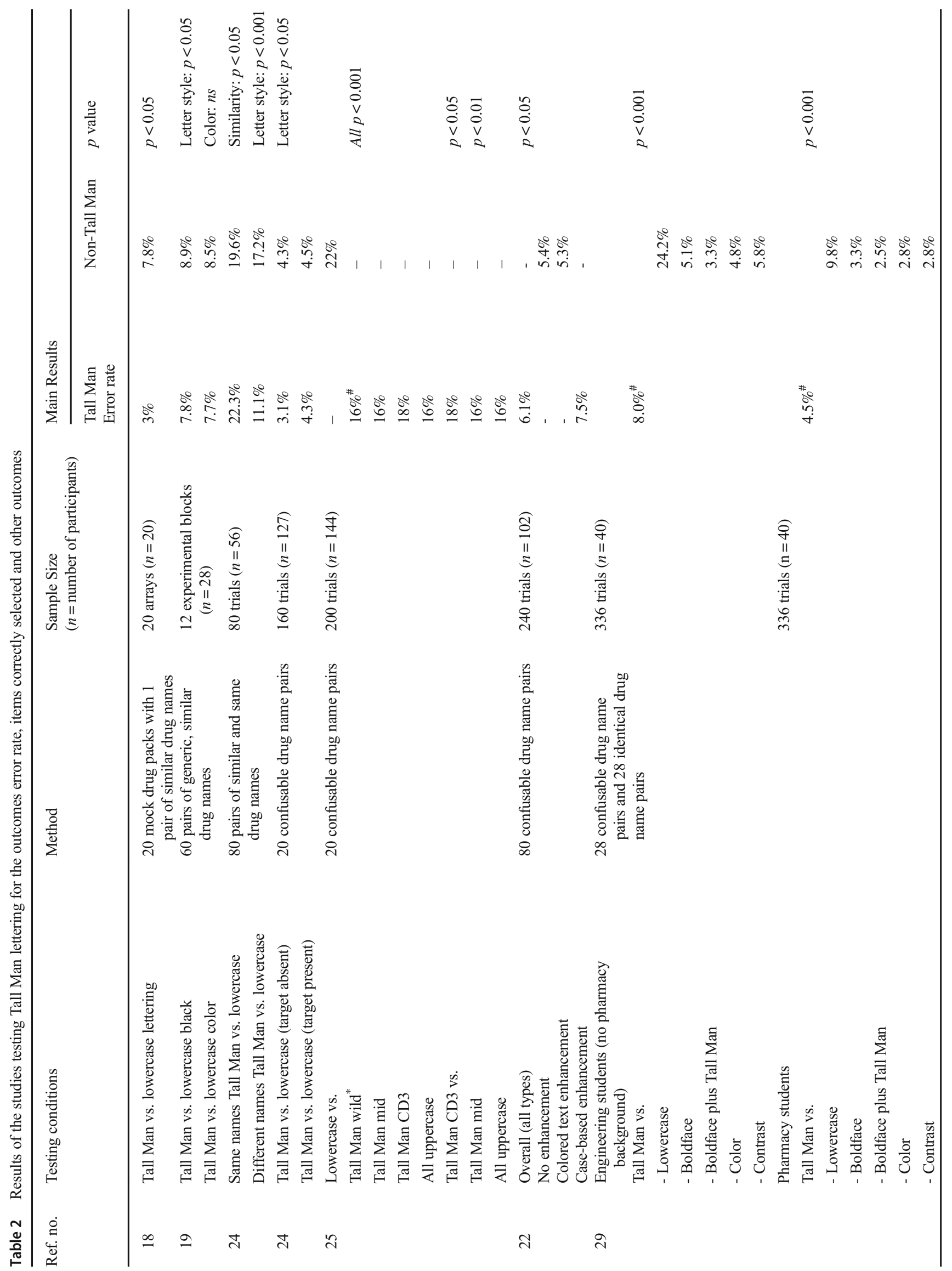




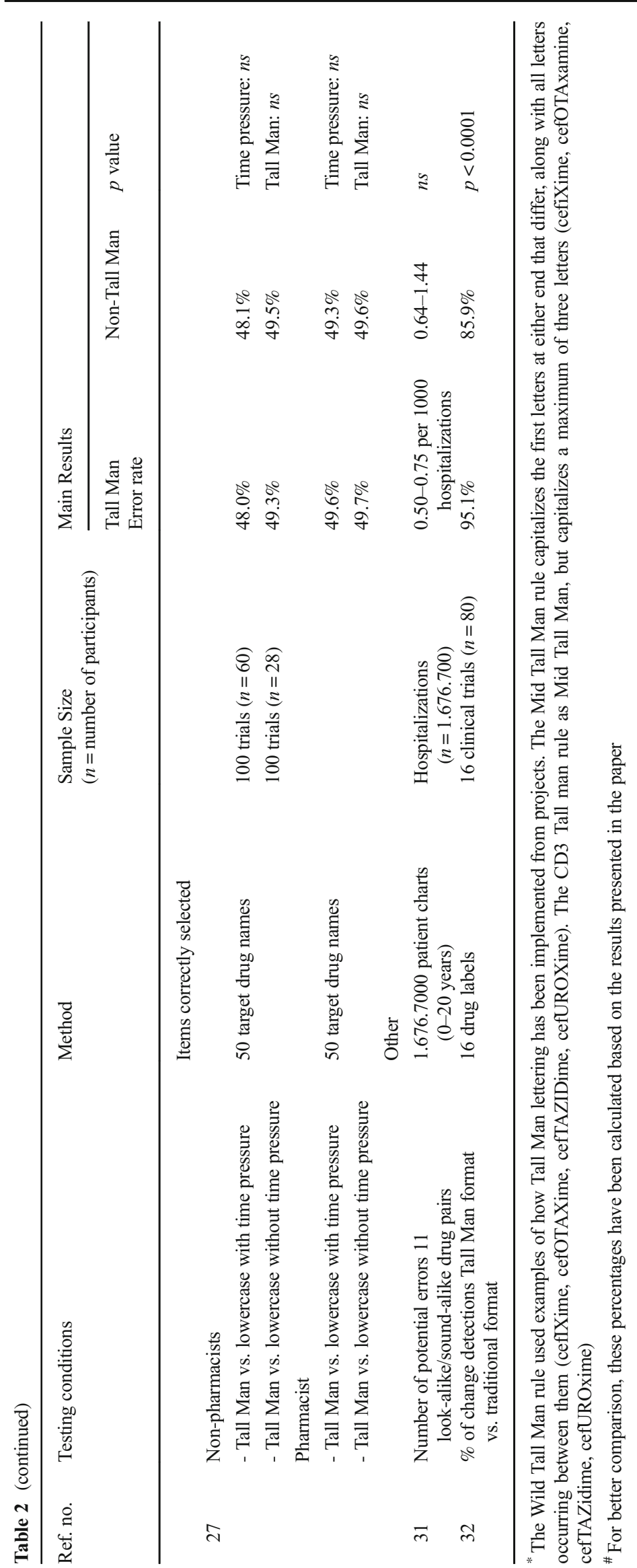


label) was significantly longer than for the new white labels. The correct reading score was higher for the ampoules with a white label than for the ampoules with text directly printed on glass or on a clear label $[21,30]$.

The study on symbol use (Table 4, Appendix) showed that the addition of symbols on labels improved the percentage correctly identified medications significantly when reading labels at a 2 -ft distance [26].

\section{Discussion}

In our systematic literature review, we found evidence from laboratory-based studies that Tall Man lettering contributes to a better readability of medication labels. There are only few studies evaluating color-coding or other strategies such as the use of symbols.

Almost all studies on Tall Man lettering showed a lower error rate, except the study by Schell [22], but examining details of the study suggests that there may have been a ceiling effect of accuracy, i.e., a very low error rate and a small sample size for one of the experiments questioning statistical testing which may explain the negative findings of this study. Most studies also assessed response time. This measure provides general information on how people may process information on the label under time pressure, e.g., due to high workload. In healthcare, high workload has been linked to declines in checking accuracy and a decrease in visual fixations resulting in error-producing conditions [33]. Studies investigating the effects of Tall Man lettering on response time are less conclusive. Only three out of nine experiments showed significant results in favor of Tall Man lettering [19, 24, 32]. Interestingly, Filik et al. showed that response time depended whether or not participants knew about the purpose of Tall Man lettering [19]. This may suggest that training may be required for optimal use of the Tall Man lettering strategy. Of note, other studies do not explicitly state whether or not participants knew about the purpose of the study. The results of Or et al. suggest that combining Tall Man lettering and greater stroke widths increases the salience of highlighted letters decreasing the difficulty of the visual search and detection which improves name differentiation [29]. In summary, the laboratory experiments show promising results for Tall Man letter strategies to make similar names less confusable perceptually and can increase attention to high-risk drug names. But details of which type of Tall Man lettering works best, for example, which part of the word should be capitalized, cannot be derived because the used pairs of drug names in the studies were different and also which specific letters were written in Tall Man lettering were different between the studies $[19,24,25]$.

In a very interesting study, Schroeder et al. found a significant relationship between drug name confusion rates in laboratory-based memory and perception tests and error rates in community pharmacy practice. In short, they were able to predict error rates based on laboratory experiments. In analogy, Tall Man lettering, could contribute to a higher level of medication safety. But it remains challenging to assess the specific contribution of one factor, like Tall Man lettering, because the administration of medication is a process in which many factors play a role $[34,35]$. By and large, real-world data are lacking. A recent time series analysis in US hospitals showed no reduction in look-alike errors after the implementation of Tall Man lettering [31]. These negative results may be due to a lack of implementation of the strategy in the hospitals. It remained unknown to what extent and when (if at all) the hospitals implemented Tall Man lettering and for which name pairs [31]. This may suggest that additional translational research is needed to identify the implementation measures needed to improve medication safety in practice using Tall Man lettering [36]. Such questions need to be answered, alongside well-conducted studies in practice to investigate the benefit or otherwise of Tall Man lettering for medication safety. This is urgent, as Tall Man lettering seems widely embraced as an error reduction strategy [7, 37, 38].

The evidence for a color-coding system is scarce. The little evidence there is suggests that color-coding does not reduce the risk of look-alike drug errors. A number of other arguments have been raised against the use of color-coding. There are far more look-alike drugs or drug groups than there are colors which could be used. Furthermore, the prevalence of congenital color vision deficiency is about $8 \%$ for men and $0.4 \%$ for women in the general population [39]. Most importantly, evidence suggests that healthcare professionals will rely solely on the color of the labels, and not read the labels at all [40, 41]. Anecdotal evidence suggests problems implementing the colorcoding system in practice [42]. Despite the lack of evidence, there is an international standard recommending color-coding in anesthesia and it seems to be the most commonly used strategy for label enhancement in anesthesia at the moment, used in multiple countries around the world, including the UK, Australia, and New Zealand [9, 43, 44].

A number of important methodological issues of the included studies have to be considered. First, as highlighted above, most experiments were conducted in a controlled laboratory environment rather than in a hospital. This restricts the generalizability of the findings to a busy ward environment with numerous other factors (workload, stress, noise, lightning) having an impact on the performance of users [13]. Second, as in other medication error research, no standard definition of what constituted an 'error' was used $[45,46]$. For example, some authors defined 'error' as the overall errors that were made; others used different categories, like omission and commission errors. 
Therefore, error rates may not be comparable between studies and this may explain that the error rates ranged between 3 and 24\%. These and other methodological differences, such as the wide range of different drug names tested, between studies made it impossible to carry out a formal meta-analysis of the data. Studies using appropriate methods and well-defined outcome measures are needed to evaluate the effects of the different label enhancement methods in practice. Such studies should be carried out before widespread implementation of label enhancement strategies.

Our study has a number of limitations which need to be considered. First, only two databases were used for the literature search as we expected that these databases contained the relevant literature. We also did not carry out a formal search of gray literature. All references of the included studies were analyzed to check for possible related studies. This resulted in six more studies which may mean that our electronic search was not as comprehensive as we intended. Nevertheless, we are confident that the electronic search combined with the hand search was successful in locating the relevant literature. Second, we only included English publications, so we may have missed studies published in other languages. Finally, we did not perform a detailed assessment of the quality of the studies as currently available instruments were not suitable for the laboratory-based studies included in our review [47].

Safer labeling of medication is only one aspect of preventing medication errors due to mixing up medications. Labeling needs to be part of a multifaceted approach involving many different aspects of the medication use process. This includes the selection of the non-sound-alike/look-alike generic and brand names during the drug development process. In practice, this concerns procedures such as double-checking of medications before administration [48], the use of technological solutions such as bar-coded drug administration [49] and consumer education [11]. But, given the scale of daily use of labels to identify medications in practice by healthcare professionals and patients, it is surprising that the fundamental question of what a medication label should look like cannot be answered adequately $[5,6]$.

\section{Conclusion}

Laboratory studies show that Tall Man lettering contributes to reduced error rates probably due to a better readability of medication labels, but evaluations in real-life setting are needed to strengthen this conclusion. There is little evidence supporting color-coding and few other methods such as symbols have been tested.
Funding information This research did not receive any specific grant from funding agencies in the public, commercial, or not-for-profit sectors.

\section{Compliance with ethical standards}

Conflict of interest The authors declare that they have no conflict of interest.

Open Access This article is distributed under the terms of the Creative Commons Attribution 4.0 International License (http:// creativecommons.org/licenses/by/4.0/), which permits unrestricted use, distribution, and reproduction in any medium, provided you give appropriate credit to the original author(s) and the source, provide a link to the Creative Commons license, and indicate if changes were made.

\section{References}

1. Berman A (2004) Reducing medication errors through naming, labeling, and packaging. J Med Syst 28(2):9-29

2. Thomas MR, Holquist C, Phillips J (2001) Medication error reports to FDA show a mixed bag. FDA Saf Page 145(19):23

3. Berdot S, Roudot M, Schramm C, Katsahian S, Durieux P, Sabatier B (2016) Interventions to reduce nurses' medication administration errors in inpatient settings: a systematic review and meta-analysis. Int J Nurs Stud 53:342-350

4. Keers RN, Williams SD, Cooke J, Ashcroft DM (2013) Causes of medication administration errors in hospitals: a systematic review of quantitative and qualitative evidence. Drug Saf 36(11):10451067

5. European Commission (2009) Guideline on the readability of the labelling and package leaflet of medicinal products for human use, revision 1. European Commission, Brussels. http://ec.europa.eu/ health/files/eudralex/vol-2/c/2009_01_12_readability_guideline final_en.pdf. Accessed 8 Apr $2016^{-}$

6. U.S. Department of Health and Human Services, Food and Drug Administration, Center for Drug Evaluation and Research (CDER) (2013) Guidance for industry; safety considerations for container labels and carton labeling design to minimize medication errors. Available at https:/www.fda.gov/Drugs/GuidanceCompliance RegulatoryInformation/Guidances/default.htm. Accessed 8 Apr 2016

7. Institute for Safe Medication Practices. FDA and ISMP lists of look-alike drug names with recommended tall man letters. Available at: http://www.ismp.org/tools/tallmanletters.pdf. Accessed 21 Jun, 2016

8. Joint Commission International (2013) Joint commission international accreditation standards for hospitals. Joint Commission International, U.S.A.

9. ISO International Standards (2008) ISO 26825:2008; Anaesthetic and respiratory equipment: User-applied labels for syringes containing drugs used during anaesthesia; colours, design and performance. ISO International Standards, Geneva

10. NHS- National Patient Safety Agency (2008) Design for patient safety: a guide to labelling and packaging of injectable medicine, ed 1. Available at: http://www.nrls.npsa.nhs.uk/resources/? entryid45=59831. Accessed 19 April 2018

11. Ostini R, Roughead EE, Kirkpatrick CMJ, Monteith GR, Tett SE (2012) Quality use of medicines - medication safety issues in naming; look-alike, sound-alike medicine names. Int J Pharm Pract 20(6):349-357 
12. Ciociano N, Bagnasco L (2014) Look alike/sound alike drugs: a literature review on causes and solutions. Int J Clin Pharm 36(2): 233-242

13. James KL, Barlow D, McArtney R, Hiom S, Roberts D, Whittlesea C (2009 Feb) Incidence, type and causes of dispensing errors: a review of the literature. Int J Pharm Pract 17(1):9-30

14. Lambert BL, Schroeder SR, Galanter WL (2016) Does Tall Man lettering prevent drug name confusion errors? Incomplete and conflicting evidence suggest need for definitive study. BMJ Qual Saf 25(4):213-217

15. Moher D, Liberati A, Tetzlaff J, Altman DG (2009) PRISMA Group. Preferred reporting items for systematic reviews and metaanalyses: the PRISMA statement. J Clin Epidemiol 62(10):10061012

16. Higgins JPT, Green S (2011) Cochrane handbook for systematic reviews of interventions, version 5.1.0 [updated March 2011]. The Cochrane Collaboration. Version 5.1.0 [updated March 2011; Available at: www.handbook.cochrane.org. Accessed 2 Sept 2015

17. Fasting S, Gisvold SE (2000) Adverse drug errors in anesthesia, and the impact of coloured syringe labels. Can J Anaesth 47(11):1060 1067

18. Filik R, Purdy K, Gale A, Gerrett D (2004) Drug name confusion: evaluating the effectiveness of capital ("Tall an") letters using eye movement data. Soc Sci Med 59(12):2597-2601

19. Filik R, Purdy K, Gale A, Gerrett D (2006) Labeling of medicines and patient safety: evaluating methods of reducing drug name confusion. Hum Factors 48(1):39-47

20. Gabriele S (2006) The role of typography in differentiating lookalike/sound-alike drug names. Healthc Q 9 Spec No:88-95

21. Momtahan K, Burns CM, Jeon J, Hyland S, Gabriele S (2008) Using human factors methods to evaluate the labelling of injectable drugs. Healthc Q 11(3 Spec):122-128

22. Schell KL (2009) Using enhanced text to facilitate recognition of drug names: evidence from two experimental studies. Appl Ergon 40(1):82-90

23. Shannon J, O'Riain S (2009) Introduction of international syringe labelling in the Republic of Ireland. Ir J Med Sci 178(3): 291-296

24. Filik R, Price J, Darker I, Gerrett D, Purdy K, Gale A (2010) The influence of tall man lettering on drug name confusion: a laboratory-based investigation in the UK using younger and older adults and healthcare practitioners. Drug Saf 33(8):677-687

25. Darker IT, Gerret D, Filik R, Purdy KJ, Gale AG (2011) The influence of 'Tall Man' lettering on errors of visual perception in the recognition of written drug names. Ergonomics 54(1):21-33

26. Cardarelli R, Mann C, Fulda KG, Balyakina E, Espinoza A, Lurie S (2011) Improving accuracy of medication identification in an older population using a medication bottle color symbol label system. BMC Fam Pract 12:142

27. Irwin A, Mearns K, Watson M, Urquhart J (2013) The effect of proximity, Tall Man lettering, and time pressure on accurate visual perception of drug names. Hum Factors 55(2):253-266

28. Or CK, Chan AH (2014) Effects of text enhancements on the differentiation performance of orthographically similar drug names. Work 48(4):521-528

29. Or CK, Wang H (2014) A comparison of the effects of different typographical methods on the recognizability of printed drug names. Drug Saf 37(5):351-359

30. Gupta B, Gupta SK, Suri S, Farooque K, Yadav N, Misra M (2015) Efficacy of contrasting background on a drug label: a prospective, randomized study. J Anaesthesiol Clin Pharmacol 31(2):230-233

31. Zhong W, Feinstein JA, Patel NS, Dai D, Feudtner C (2016) Tall man lettering and potential prescription errors: a time series analysis of 42 children's hospitals in the USA over 9 years. BMJ Qual Saf 25(4):233-240

32. DeHenau C, Becker MW, Bello NM, Liu S, Bix L (2016) Tallman lettering as a strategy for differentiation in look-alike, sound-alike drug names: the role of familiarity in differentiating drug doppelgangers. Appl Ergon 52:77-84

33. Kataoka J, Sasaki M, Kanda K (2011) Effects of mental workload on nurses' visual behaviors during infusion pump operation. Jpn J Nurs Sci 8(1):47-56

34. Trbovich PL, Hyland S (2017) Responding to the challenge of lookalike, sound-alike drug names. BMJ Qual Saf 26(5):357-359

35. Schroeder SR, Salomon MM, Galanter WL, Schiff GD, Vaida AJ, Gaunt MJ, Bryson ML, Rash C, Falck S, Lambert BL (2017) Cognitive tests predict real-world errors: the relationship between drug name confusion rates in laboratory-based memory and perception tests and corresponding error rates in large pharmacy chains. BMJ Qual Saf 26(5):395-407

36. Westfall JM, Mold J, Fagnan L (2007) Practice-based research-"Blue Highways" on the NIH roadmap. JAMA 297(4):403-406

37. Grissinger $\mathrm{M}(2012)$ Tall man letters are gaining wide acceptance. $\mathrm{P}$ T 37(3):132-148

38. Institute for Safe Medication Practices Canada (2015) Application of TALLman lettering for selected high-alert drugs in Canada. ISMP Canada Safety Bulletin 15(10):1-3. http://www.ismpcanada.org/download/safetyBulletins/2015/ISMPCSB2015-10 TALLman.pdf. Accessed 30 Oct 2015

39. Spalding JA (1999 Jun) Colour vision deficiency in the medical profession. Br J Gen Pract 49(443):469-475

40. Filiatrault $P$ (2009) Does colour-coded labelling reduce the risk of medication errors? Can J Hosp Pharm 62(2):154-155

41. Institute for Safe Medication Practices (2003) How color-coding products, such as cyclopentolate hydrochloride $1 \%$ solution and tropicamide $1 \%$ solution, can lead to medication errors. Acute care ISMP Medication Safety Alert. Available at http://www.ismp.org. Accessed 21 Jun 2016

42. Watts J (2016 Mar) More on the risks of inconsistent drug packaging and ampoule labelling. Anaesthesia 71(3):348-349

43. Birks RJ, Simpson PJ (2003) Syringe labelling-an international standard. Anaesthesia 58(6):518-519

44. Australian Commission on Safety and Quality in Health Care, and the Australian and New Zealand College of Anaesthetists (2013) A joint statement supporting user-applied labelling standardisation for all injectable medicines and fluids. Available at: http://www. safetyandquality.gov.au/wp-content/uploads/2012/02/ANZCAand-Commission-Joint-statement-on-user-applied-labellingstandardisation.pdf. Accessed 21 Jun 2016

45. Keers RN, Williams SD, Cooke J, Ashcroft DM (2013) Prevalence and nature of medication administration errors in health care settings: a systematic review of direct observational evidence. Ann Pharmacother 47(2):237-256

46. Berdot S, Gillaizeau F, Caruba T, Prognon P, Durieux P, Sabatier B (2013) Drug administration errors in hospital inpatients: a systematic review. PLoS One 8(6):e68856

47. Page MJ, McKenzie JE, Higgins JPT (2018) Tools for assessing risk of reporting biases in studies and syntheses of studies: a systematic review. BMJ Open 8(3): 019703

48. Schwappach DL, Pfeiffer Y, Taxis K (2016) Medication doublechecking procedures in clinical practice: a cross-sectional survey of oncology nurses' experiences. BMJ Open 6(6):e011394

49. van der Veen W, van den Bemt PMLA, Wouters H, Bates DW, Twisk JWR, de Gier JJ, et al (2018) Association between workarounds and medication administration errors in bar-codeassisted medication administration in hospitals. J Am Med Inform Assoc 25(4):385-392 